\title{
Hemodiyalizde Rutinde Ölçülen Kan Basıncı Değerlerinin Standartlara Uygun Ölçülen Kan Basıncı Değerleri ile Karşılaştırılması
}

\section{Comparison of Blood Pressure Values Measured Routinely with the Values Measured Accordingly to the Standards in Hemodialysis}

\section{Derya DUMAN ${ }^{1}$, Emre ERDEM $^{2}$, Tevfik ECDER ${ }^{3}$}

${ }^{1}$ Hemşire- Dmed Özel Merzifon Diyaliz Merkezi, Amasya, Türkiye

${ }^{2}$ Uzman Dr.- Dmed Özel Merzifon Diyaliz Merkezi, Amasya, Türkiye

${ }^{3}$ Prof. Dr.- Demiroğlu Bilim Üniversitesi, Nefroloji Bilim Dalı, İstanbul, Türkiye

* Çalışma, 3-7 Ekim 2018 tarihlerinde Antalya'da gerçekleştirilen 28. Ulusal Böbrek Hastalıkları, Diyaliz ve Transplantasyon Hemşireliği Kongresi’nde sözel bildiri olarak sunulmuştur.

Geliş Tarihi / Received :

28 Mayis 2020

Kabul Tarihi / Accepted:

26 Eylül 2020

\section{İletişim yazarı}

Correspondence author

Emre ERDEM

E-posta: emredlk@yahoo.com

\section{ORCID:}

Derya DUMAN

https://orcid.org/0000-0001-7233-4550

Emre ERDEM

https://orcid.org/0000-0002-3091-2583

Tevfik ECDER

https://orcid.org/0000-0003-3394-5775

\section{Özet}

Amaç: Çalışmada hemodiyaliz öncesi ve sonrası rutin pratikte ölçülen kan basıncı değerlerinin hemodiyaliz öncesi ve sonrası kılavuzların önerdiği şekilde standartlara uygun ölçülen kan basıncı değerlerinden ne kadar farklı olduğunu araştırdık.

Gereç ve Yöntemler: Çalışma 76 hemodiyaliz hastası ile gerçekleştirildi. Hastalar hemodiyaliz merkezine geldikten sonra kılavuzların önerdiği şekilde standartlara uygun kan basıncı ölçümü yapıldı. Hastaların standart kan basıncı ölçüldükten sonra diyaliz öncesi rutin kan basınçları ölçüldü. Diyaliz tamamlandıktan sonra hastaların diyaliz sonrası rutin ve standartlara uygun kan basıncı ölçümleri yapıldı.

Bulgular: Hastaların hemodiyaliz öncesi standartlara uygun ölçülen sistolik kan basınc1 (SKB) ortalaması, rutin ölçülen SKB ortalamasından daha düşüktü (129 \pm 25 vs. $134 \pm 25 \mathrm{~mm} \mathrm{Hg}$; $<<0.0001)$. Hemodiyaliz öncesi standart diyastolik kan basıncı (DKB) ortalaması da, rutin DKB ortalamasından daha düşüktü (74 \pm 12 vs. $77 \pm 14 \mathrm{~mm} \mathrm{Hg}$; $<<0.0001$ ). Hemodiyaliz sonrası ölçümlerde ise standart SKB ortalaması ile rutin SKB ortalaması arasında anlamlı fark yoktu $(115 \pm 24$ vs 113 $\pm 26 ; \mathrm{p}>0.05)$. Hemodiyaliz sonrası standart $\mathrm{DKB}$ ortalamas1, rutin DKB ortalamasından daha yüksek idi ( $71 \pm 12$ vs. $68 \pm 14 \mathrm{~mm} \mathrm{Hg}$; $\mathrm{p}=0.043)$.

Sonuç: Hemodiyaliz öncesi standartlara uygun ölçülen SKB ve DKB, rutin ölçümlere göre sıklıkla daha düşüktür.

Anahtar kelimeler: Kan basıncı; Kan basıncı ölçümü; Hemodiyaliz 


\begin{abstract}
Objective: In this study, we investigated how predialysis and post-dialysis blood pressure values measured in routine practice differ from the blood pressure values measured accordingly to the standards, as suggested by the guidelines.

Material and Methods: This study was performed with 76 hemodialysis patients. After the patients came to the hemodialysis center, blood pressure measurement was performed accordingly to the standards as recommended by the guidelines. After the standard blood pressure of the patients were measured, routine predialysis blood pressures were measured. After dialysis was completed, postdialysis blood pressure measurements of patients accordingly to routine and standards were performed.

Results: The mean predialysis standard systolic blood pressure (SBP) value was lower than the mean routine SBP value $(129 \pm 25 \mathrm{vs} .134 \pm 25 \mathrm{mmHg} ; \mathrm{p}<0.0001)$. The mean predialysis standard diastolic blood pressure (DBP) value as well as lower than the mean routine DBP value $(74 \pm 12$ vs. $77 \pm 14 \mathrm{mmHg}$; $<<0.0001)$. The mean post-dialysis SBP values were not significantly different between the standard and routine measurements $(115 \pm 24$ vs $113 \pm 26 ; \mathrm{p}>0.05)$. The mean post-dialysis standard DBP measurement was higher than the routine DBP $(71 \pm 12$ vs. $68 \pm 14 \mathrm{mmHg}$; $=0.043$ ).
\end{abstract}

Conclusion: Predialysis standard SBP and DBP measurements are usually lower than the routine measurements.

Keywords: Blood pressure; Blood pressure measurement; Hemodialysis

\section{GİRIŞ}

Hemodiyaliz öncesi hastalar kan basıncı, kilo, nabız, ateş, ödem gibi parametreler ile değerlendirilmektedir. Hastaların hemodinamik durumunu değerlendirmek için hemodiyaliz tedavisi öncesinde, tedavi sürecince ve hemodiyaliz bittikten sonra kan basıncı takibi yapılır. Hemodiyaliz öncesi ve sonrası ölçülen kan basıncı değeri kardiyovasküler mortalite göstergesi olarak kullanılmıştır. Hem yüksek kan basıncı hem de düşük kan basıncı değerleri artmış mortalite ile ilişkilidir (1-4). Diyaliz tedavisi sırasında ölçülen kan basıncı ayrıca hastanın kardiyovasküler hemodinamik durumu hakkında bilgi vermektedir $(4,5)$.

Kan basıncı doğru sonuç göstermesi için doğru bir şekilde ölçülmelidir. Kan basıncının standartlara uygun, doğru bir şekilde nasıl ölçüleceği k1lavuzlar ile tarif edilmiştir (4). Doğru kan basıncı ölçümü için hasta kan basıncı ölçülmeden önce en az 5 dakika istirahat etmelidir. Tansiyon aletinin manşonunun boyutu kol çevresine uygun olmalıdır. Kan basıncı ölçerken koldaki giysiler çıkartılmalıdır. Hastanın kolu desteklenmelidir.
Tansiyon aletinin manşonu alt ucu dirseğin 2.5-3 $\mathrm{cm}$ üzerinde olacak şekilde kolu sarmalıdır. Hasta sırtını bir yere yaslayarak oturmalı, ölçüm sırasında konuşmamalı, bacak bacak üstüne atmamalıdır. Ayakları yere basar şekilde olmalıdır. Hemodiyaliz tedavisine başlamadan önce kan basıncı ölçümü arteriyovenöz fistül (AVF) iğnesi takılmadan en az beş dakika önce yapılmalıdır. (4). Kan basıncının kılavuzların önerdiği şekilde standartlara uygun ölçülmemesi, diyaliz öncesi ve sonrası kan basıncı değerlerini olduğundan farklı bulmamıza neden olabilir. Doğru şekilde kan basıncı ölçülmez ise kan basıncı olduğundan daha yüksek veya daha düşük çıkabilir (5-8). Rutin günlük hemodiyalizde ise kan basıncı ölçümünde her zaman standartlara uygun ölçüm yapılamayabilmektedir. Rutin günlük pratikte hemodiyaliz öncesi ölçümlerde hastanın hemen hemodiyalize girmek istemesi nedeni ile yeteri kadar dinlenmemesi, uygun olmayan pozisyonda ölçüm yapılması, hasta kolunun desteklenmemesi, hastanın konuşması doğru kan basıncı ölçümünü önler $(7,8)$. Hemodiyaliz sonrası ölçümler ise daha çok hastanın volüm durumunu yansıtır. Ultrafiltrasyon ile hemodiyaliz sırasında çekilen 
S1v1 miktarı genelde hastanın hemodiyaliz sonras kan basıncı değerini etkiler. Yüksek ultrafiltrasyon hızı ile daha düşük kan basıncı olabilir (5). Ayrıca günlük rutin pratikte hastanın hemen diyalizden gitmek istemesi, hemodiyaliz sonrası AVF iğne çıkış yerlerine baskı uygulaması da hemodiyaliz sonrası kan basincinın tam standartlara uygun ölçülmesine engel olur $(7,8)$.

Çalışmamızda hemodiyaliz tedavisi öncesi ve sonrasında rutinde yapılan kan basıncı ölçümleri ile standartlara uygun yapılan kan basıncı ölçümlerinin sonuçlarının karşılaştırılması amaçlanmıştır.

\section{GEREÇ ve YÖNTEMLER}

Çalışma Amasya ilinin bir ilçesindeki özel bir diyaliz merkezi gerçekleştirildi. Araştırma evrenini bu diyaliz merkezinde kayıtll olarak tedavi alan tüm hastalar oluş̧urdu. Evreni oluşturan tüm hastalar gönüllülük esasına dayalı olarak çalışmaya dahil edildi ve örneklem 76 hemodiyaliz hastasından oluştu.

Hemodiyaliz ünitesinde rutin olarak ölçülen kan basıncı değerleri ile kılavuzların önerdiği şekilde standartlara uygun ölçülen kan basıncı değerleri karşılaştırıldı. Hastalar hemodiyaliz merkezine geldikten sonra kılavuzların önerdiği şekilde standart kan basıncı ölçümü yapıldı $(4,9)$. Tüm kan basıncı ölçümleri standardizasyonu sağlamak açısından tek ve aynı araştırmacı tarafindan yapıldı. Hemodiyaliz öncesi standart kan basıncı ölçümü için hasta sessiz bir odada 5 dakika bir sandalyede dinlendirildi. Sirtı sandalyeye dayalı, kolları kalp seviyesinde ve ayakları yere basar pozisyonda idi. Tansiyon aletinde hastanın kol çevresine uygun manşon kullanıldı. Ölçüm 1 dakika ara ile iki kez yapıldı. Ölçümlerin ortalamas1 alındı. Standartlara uygun kan basinc1 ölçüldükten sonra hastalar hemodiyaliz salonuna geçtiler ve hastalar hemodiyaliz için yatağa uzandıktan sonra rutin kan basıncı ölçümü yapıld. Hemodiyaliz rutin kan basıncı hastanın iğnesi yerleştirilmeden önce ölçüldü. Hemodiyaliz tedavisi bittikten sonra hastalara rutin hemodiyaliz sonrası kan basıncı ölçümü yapıldı. Rutin hemodiyaliz sonrası kan basıncı ölçümü hastanın AVF iğnesi çekildikten sonra yatakta uzanırken yapıld1. Daha sonra hastalar hemodiyaliz sonras1 standartlara uygun kan basıncı ölçümü için 5 dakika süreyle bir sandalyede oturtuldu. Sirt1 sandalyeye dayalı, kolları kalp seviyesinde ve ayaklar1 yere basar pozisyonda idi. Sonra hemodiyaliz sonras1 standartlara uygun kan basinc1 ölçümü yapıldı.

Hastaların kan basinc1 AVF olmayan koldan ölçüldü. Kateteri olan hastaların kan basıncı ise hep aynı koldan ölçüldü. Bacaktan kan basınc1 takibi yapılan hastalar ve sandalyede oturamayacak durumda olan hastalar çalışmaya dahil edilmedi. Tüm ölçümlerde aynı otomatik kan basınc1 ölçüm cihazı kullanıldı (Omron M2 intellisense, Omron Healthcare, Kyoto, Japan).

Çalışmamız Helsinki Deklerasyonu Prensipleri'ne uygun yapılmıştır. Çalışmamız için etik kurul onayı alınmıştır. Çalışmaya katılmış bireylerden "Bilgilendirilmiş Olur Formu" ile yazılı onam alınmıştır.

\section{İstatistiksel analiz}

Değişkenlerin normal dağılıma uygunluğu Kolmogorov-Smirnov testi ile incelendi. Tanımlayıcı istatistikler normal dağılan değişkenler için ortalama \pm standart sapma verilerek yapıldı. Tanımlayıcı analizlerde normal dağılmayan değişkenler için ortanca ve çeyreklerarası aralık (\%25-\%75) kullanıldı. Standart ve rutin kan basıncı ölçümlerinin karşılaştırılmasında bağımlı gruplar (paired) Student $\mathrm{t}$ testi kullanıldı. $\mathrm{p}$ değerinin 0.05 'in altında olduğu durumlar istatistiksel olarak anlamlı kabul edildi.

\section{BULGULAR}

Çalışma 76 hemodiyaliz hastası ile yapıldı. Hastaların \%57'sinin erkek ve yaş ortalaması 64 \pm 12 (19-87) y1l idi. Hemodiyaliz girme süresi ortanca değeri 56 (29-106) ay idi. Hastaların $\% 91$ 'inde AVF, \%9'unda hemodiyaliz kateteri vard1 (Tablo 1).

Hastaların hemodiyaliz öncesi standartlara uygun ölçülen sistolik kan basıncı (SKB) ortalaması, rutin ölçülen SKB ortalamasından daha düşüktü $(129 \pm 25$ vs. $134 \pm 25 \mathrm{~mm} \mathrm{Hg} ; \mathrm{p}<0.0001)$. Hemodiyaliz öncesi standartlara uygun ölçülen diyastolik kan basıncı (DKB) ortalaması da, rutin DKB ortalamasından daha düşüktü (74 \pm 12 vs. 
$77 \pm 14 \mathrm{~mm} \mathrm{Hg} ; \mathrm{p}<0.0001)$. Hemodiyaliz sonras1 ölçümlerde standartlara uygun ölçülen SKB ortalaması, rutin SKB ortalamasindan daha yüksek olmasına rağmen bu fark istatistiksel olarak anlamlı değildi ( $>0.05)$. Hemodiyaliz sonrası ölçümlerde standartlara uygun ölçülen DKB ortalamas1, rutin ölçülen DKB ortalamasından daha yüksekti ( $71 \pm 12$ vs. $68 \pm 14 \mathrm{~mm}$ $\mathrm{Hg} ; \mathrm{p}=0.043$ ) (Tablo 2).

Tablo 1. Hastaların sosyodemografik özellikleri

\begin{tabular}{|l|c|}
\hline Yaş (yıl) & $\mathbf{6 4} \pm \mathbf{1 2}$ \\
\hline Cinsiyet & \\
\hline Kadın, n (\%) & $33(\% 43)$ \\
\hline Erkek, n (\%) & $43(\% 57)$ \\
\hline Hemodiyaliz süresi (ay) & $56(29-106)$ \\
\hline Hemodiyaliz giriş yolu & \\
\hline Arteriyovenöz fistül, n (\%) & $69(\% 91)$ \\
\hline Katater, n (\%) & $7(\% 9)$ \\
\hline Toplam hasta sayısı & 76 \\
\hline
\end{tabular}

\section{TARTIŞMA}

Çalışmamızda hemodiyaliz hastalarında kılavuzların önerdiği şekilde standartlara uygun ölçülen kan basıncının rutin günlük pratikte ölçülen kan basıncından farklı olduğu tespit edildi. Hemodiyaliz öncesi standartlara uygun ölçülen SKB ortalaması ile DKB ortalaması, rutin pratikte ölçülen kan basıncı ölçümlerine göre daha düşüktü. Hemodiyaliz sonrası ölçümlerde standartlara uygun ölçülen SKB ortalaması ile rutin SKB ortalaması arasında anlamlı fark yok iken, DKB ortalaması standartlara uygun ölçümde daha yüksekti.
Hemodiyaliz öncesi standartlara uygun ölçülen kan basıncının rutin ölçümden daha düşük olmasının sebebi standartlara uygun ölçümün kılavuzlara göre yapılması olabilir. Rutin kan basınc1 ölçümünün daha yüksek olmasının nedeni, standartlara uygun olmayan pozisyonda kan basinc1 ölçülmesi, iğne korkusu, diyaliz salonunun gürültülü olması ve kan basıncı ölçülürken hastanın konuşmas1 gibi etkenler olabilir. $\mathrm{Bu}$ tür etkenler hastanın kan basıncının normalden yüksek çıkmasına neden olmuş olabilir $(5,8)$. Literatürde çalışma sonuçlarımızı destekleyen başka çalışmalar da bulunmaktadır. Rahman et al. (2002) (10) ve Agarwal ve ark. (2006) (11) çalışmamıza benzer şekilde hemodiyaliz öncesi standartlara uygun ölçülen SKB ortalamasını ve DKB ortalamasını, rutin kan basıncı ölçümlerine göre daha düşük olduğu bulmuşlardır. Bunların aksine Kubrusly ve ark. (2006) hemodiyaliz öncesi standartlara uygun ölçülen SKB ortalamasını ve DKB ortalamasını rutin kan basıncı ölçümlerinden daha yüksek tespit etmiştir (12).

Hemodiyaliz sonrası ölçümlerde ise standartlara uygun ölçülen SKB ortalaması rutin ölçüme göre daha yüksekti ancak bu fark istatistiksel olarak anlamlı değildi. DKB ortalaması ise istatistiksel anlamlı şekilde standartlara uygun ölçümde daha yüksekti. Ultrafiltrasyon hızı hemodiyaliz sonrası kan basıncı değerini önemli ölçüde etkileyebilir. Yüksek ultrafiltrasyon hızı hemodiyaliz sonrası kan basıncı değerinin düşük çıkmasına yol açar $(4,13)$. Hemodiyalizde ultrafiltrasyon ile hastaların kan volümü azalır ve bunun sonucu diyaliz sonrası kan basıncı değerleri diyaliz öncesine göre azalır. Kan volümünün interstisyel kompartmandan vasküler alana tekrar dolması ile kan

Tablo 2. Hemodiyaliz öncesi ve sonrası standartlara uygun ölçülen ve rutin ölçülen kan basıncı ortalama değerlerinin karşılaştırılması

\begin{tabular}{|l|c|c|c|}
\cline { 2 - 4 } \multicolumn{1}{c|}{} & $\begin{array}{c}\text { Rutin ölçüm } \\
\text { (ortalama } \pm \text { SS })\end{array}$ & $\begin{array}{c}\text { Standart ölçüm } \\
\text { (ortalama } \pm \text { SS) }\end{array}$ & p değeri \\
\hline Hemodiyaliz öncesi & & & \\
\hline SKB, mmHg & $134 \pm 25$ & $129 \pm 25$ & $<0.0001$ \\
\hline DKB, mmHg & $77 \pm 14$ & $74 \pm 12$ & $<0.0001$ \\
\hline Hemodiyaliz sonrası & & & 0.136 \\
\hline SKB, mmHg & $113 \pm 26$ & $115 \pm 24$ & 0.043 \\
\hline DKB, mmHg & $68 \pm 14$ & $71 \pm 12$ & \\
\hline
\end{tabular}

SKB: sistolik kan basınc1; DKB: diyastolik kan basınc1; SS: standart sapma 
basıncı tekrar artar (14). Çalışmamızda hemodiyaliz sonrası kan basıncı ölçümlerinde standartlara uygun ölçüm, rutin ölçümünden daha sonra yapılmıştır. Hemodiyaliz sonlandırıldıktan sonra rutin kan basıncı ölçümü yapılmış daha sonra hasta beş dakika bir sandalyede dinlendirilerek standartlara uygun kan basıncı ölçümü yapılmıştır. $\mathrm{Bu}$ sürede kan volümünün interstisyel kompartmandan vasküler alana tekrar dolması sonucu kan basıncı artmış ve standartlara uygun ölçülen kan basıncı değeri rutin ölçüme göre daha yüksek çıkmış olabilir. Bizim çalışmamızın aksine Rahman ve ark. (10) ve Agarwal ve ark. (11) hemodiyaliz sonras1 standartlara uygun ölçülen SKB ortalamasını ve DKB ortalamasını, rutin kan basıncı ölçümlerinden daha düşük bulmuşlardır.

\section{SONUÇ}

Sonuç olarak hemodiyaliz ünitelerinde standartlara uygun ölçülen kan basıncı ile rutin ölçülen kan basincı arasında belirgin farklılık vardır. Kılavuzların önerdiği şekilde standartlara uygun ölçülen diyaliz öncesi $\mathrm{SKB}$ ve DKB, rutin kan basıncı değerlerine göre genellikle daha düşüktür. Diyaliz ünitelerinde kan basıncı ölçümlerini kılavuzların önerdiği şekilde standartlara uygun yapmak kan basıncını daha doğru gösterebilir.

\section{Kaynaklar}

1. Khan YH, Sarriff A, Adnan AS, Khan AH, Mallhi TH. Blood Pressure and Mortality in Hemodialysis Patients: A Systematic Review of an Ongoing Debate. Ther Apher Dial 2016; 20(5): 453-461.

2. Agarwal R. Blood pressure and mortality among hemodialysis patients. Hypertension 2010; 55(3): 762-768.

3. Hörl MP, Hörl WH. Hemodialysis-associated hypertension: pathophysiology and therapy. Am J Kidney Dis 2002; 39(2): 227-244.

4. K/DOQI Workgroup. K/DOQI clinical practice guidelines for cardiovascular disease in dialysis patients. Am J Kidney Dis 2005; 45(4 Suppl 3): S1-153.

5. Sarafidis PA, Persu A, Agarwal R, Burnier M, de Leeuw P, et al. Hypertension in dialysis patients: a consensus document by the European Renal and Cardiovascular Medicine (EURECA-m) working group of the European Renal Association-European Dialysis and Transplant Association (ERA-EDTA) and the Hypertension and the Kidney working group of the European Society of Hypertension (ESH). Nephrol Dial Transplant 2017; 32(4): 620-640.

6. Akpolat T, Kaya C, Utaş C, Arinsoy T, Taşkapan H, et al. Arm circumference: its importance for dialysis patients in the obesity era. Int Urol Nephrol 2013; 45(4): 1103-1110.

7. Sankaranarayanan N, Santos SF, Peixoto AJ. Blood pressure measurement in dialysis patients. Adv Chronic Kidney Dis 2004; 11(2): 134-142.

8. Lazar AE, Smith MC, Rahman M. Blood Pressure Measurement in Hemodialysis Patients. Semin Dial 2004; 17(4): 250-254.

9. Chobanian AV, Bakris GL, Black HR, Cushman WC, Green LA, et al. National Heart, Lung, and Blood Institute Joint National Committee on Prevention, Detection, Evaluation, and Treatment of High Blood Pressure; National High Blood Pressure Education Program Coordinating Committee. The Seventh Report of the Joint National Committee on Prevention, Detection, Evaluation, and Treatment of High Blood Pressure: the JNC 7 report. JAMA 2003; 289(19): 2560-2572.

10. Rahman M, Griffin V, Kumar A, Manzoor F, Wright JT Jr, et al. A comparison of standardized versus "usual" blood pressure measurements in hemodialysis patients. Am J Kidney Dis 2002; 39(6): 1226-1230.

11. Agarwal R, Brim NJ, Mahenthiran J, Andersen MJ, Saha C. Out-of-hemodialysis-unit blood pressure is a superior determinant of left ventricular hypertrophy. Hypertension 2006; 47(1): 62-68.

12. Kubrusly M, de Oliveira CM, Silva RP, Pinheiro MA, Rocha MB, et al. Blood pressure measurement in hemodialysis: The importance of the measurement technique. Saudi J Kidney Dis Transpl 2006; 27(2): 241-249.

13. Erdem E. The effects of passive leg raising and ultrafiltration stopping on blood pressure in hemodialysis patients. Int Urol Nephrol 2016; 48(6): 877-882.

14. Kooman J, Basci A, Pizzarelli F, Canaud B, Haage P, et al. EBPG guideline on haemodynamic instability. Nephrol Dial Transplant 2007; 22 (Suppl 2): ii22-44. 